\title{
How the Strain Origin of ZIKV NS1 Protein Impacts its Dynamics and Implications to their Differential Virulence
}

Sergio A. Poveda-Cuevas ${ }^{\mathrm{a}, \mathrm{b}, \mathrm{g}}$, Fernando L. Barroso da Silva ${ }^{\mathrm{a}, \mathrm{b}, \mathrm{c}, \mathrm{g}}$ and Catherine Etchebest ${ }^{\mathrm{d}, \mathrm{e}, \mathrm{f}, \mathrm{g}{ }^{*}}$

${ }^{a}$ Universidade de São Paulo, Programa Interunidades em Bioinformática, Rua do Matão, 1010, BR, 05508-090 São Paulo, São Paulo, Brazil.

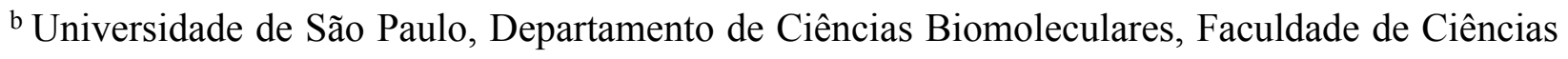
Farmacêuticas de Ribeirão Preto, Av. do Café, s/no-Campus da USP, BR, 14040-903 Ribeirão Preto, São Paulo, Brazil.

c Department of Chemical and Biomolecular Engineering, North Carolina State University, Raleigh, NC 27695, United States.

d Institut National de la Transfusion Sanguine, 6 Rue Alexandre Cabanel, 75015 Paris, France.

e Institut National de la Santé et de la Recherche Médicale, UMR_S 1134, Biologie Intégrée du Globule Rouge, Equipe 2, INSERM, Dynamique des Structures et des Interactions Moléculaires, F-75015 Paris, France.

${ }^{\mathrm{f}}$ Université de Paris, 5 Rue Thomas Mann, 75013 Paris, France.

g University of São Paulo and Université de Paris International Laboratory in Structural Bioinformatics, Faculdade de Ciências Farmacêuticas de Ribeirão Preto, Av. do Café, s/noCampus da USP, Bloco B, BR, 14040-903 Ribeirão Preto, São Paulo, Brazil.

* Corresponding Author

E-mail: catherine.etchebest@inserm.fr 


\section{SUPPORTING INFORMATION}

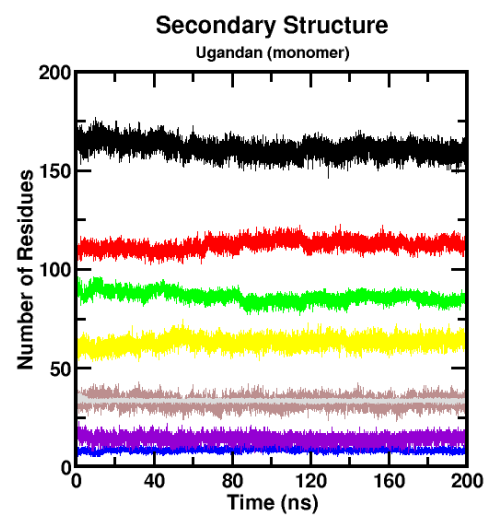

(a)

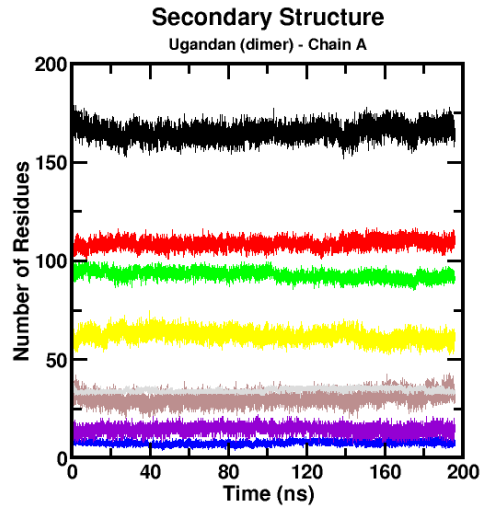

(c)

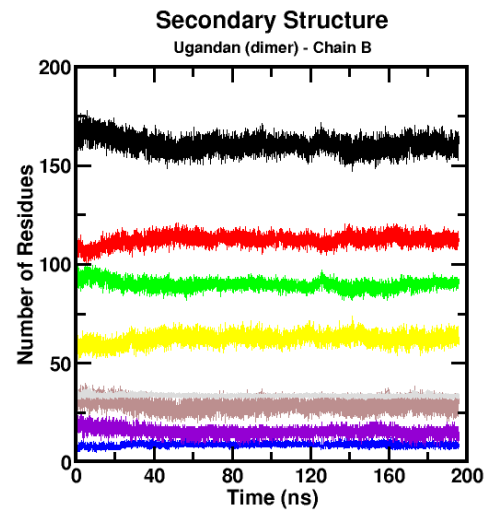

Structure (161 \pm )

Coil $(112 \pm 5)$

$\beta$-Sheet $(90 \pm 4)$

$\beta$-Bridge $(9 \pm 2)$

Turn $(29 \pm 4)$

$\alpha$-Helix (34 \pm 1$)$

3-Helix (15 \pm 3 )

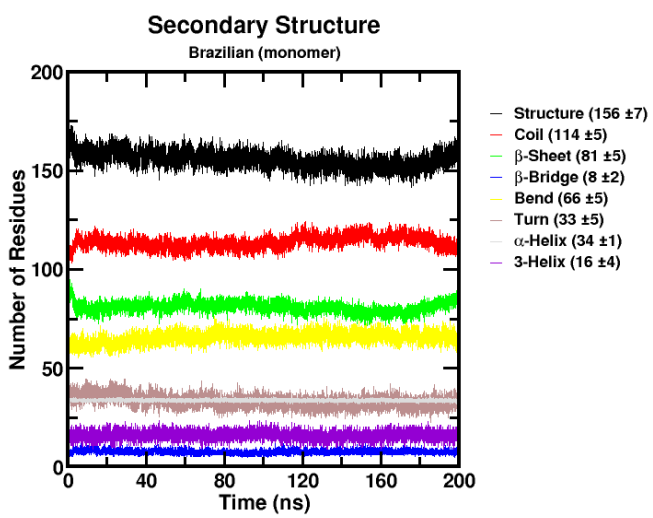

(b)

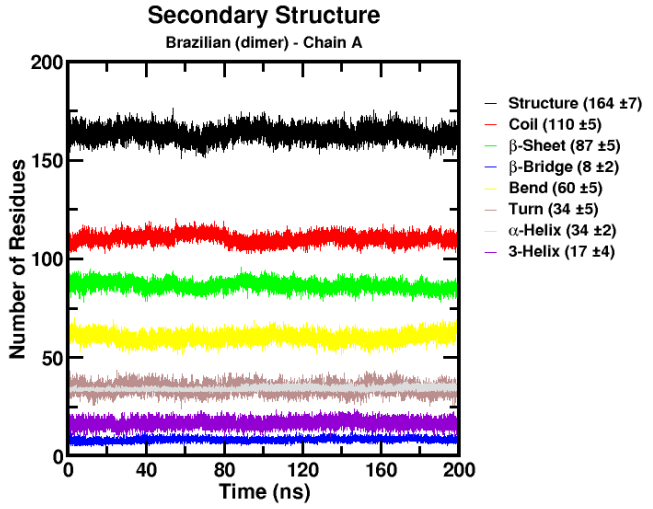

(d)

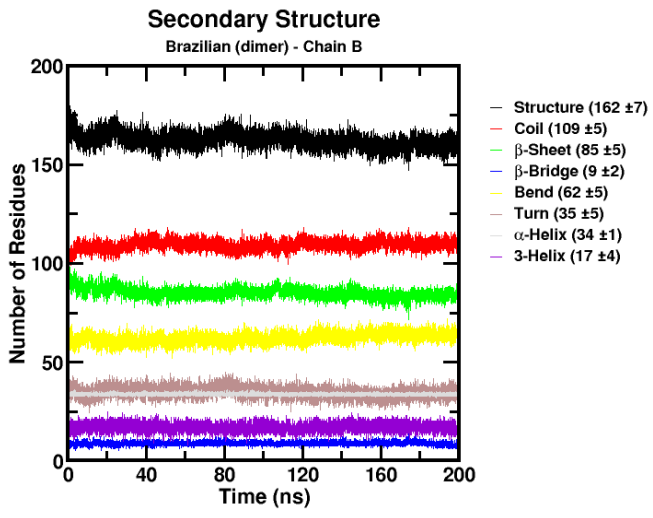

(f) 
Figure S1. Number of residues with a particular secondary structure (SS) as a function of time (200 ns) for $\mathrm{NS}_{\mathrm{UG}}(\mathrm{PDB}$ id $5 \mathrm{~K} 6 \mathrm{~K})$ and $\mathrm{NS}_{\mathrm{BR}}(\mathrm{PDB}$ id 5GS6) at all-atoms representation. (a) SS for the $\mathrm{NS}_{\mathrm{UG}}$ monomer. (c) SS for the chain $\mathrm{A}$ of $\mathrm{NS} 1_{\mathrm{UG}}$ dimer. (e) SS for the chain $\mathrm{B}$ of $\mathrm{NS} 1_{\mathrm{UG}}$ dimer. (b) SS for the $\mathrm{NS}_{\mathrm{BR}}$ monomer. (d) $\mathrm{SS}$ for the chain $\mathrm{A}$ of $\mathrm{NS} 1_{\mathrm{BR}}$ dimer. (f) $\mathrm{SS}$ for the chain $\mathrm{B}$ of $\mathrm{NS} 1_{\mathrm{BR}}$ dimer.

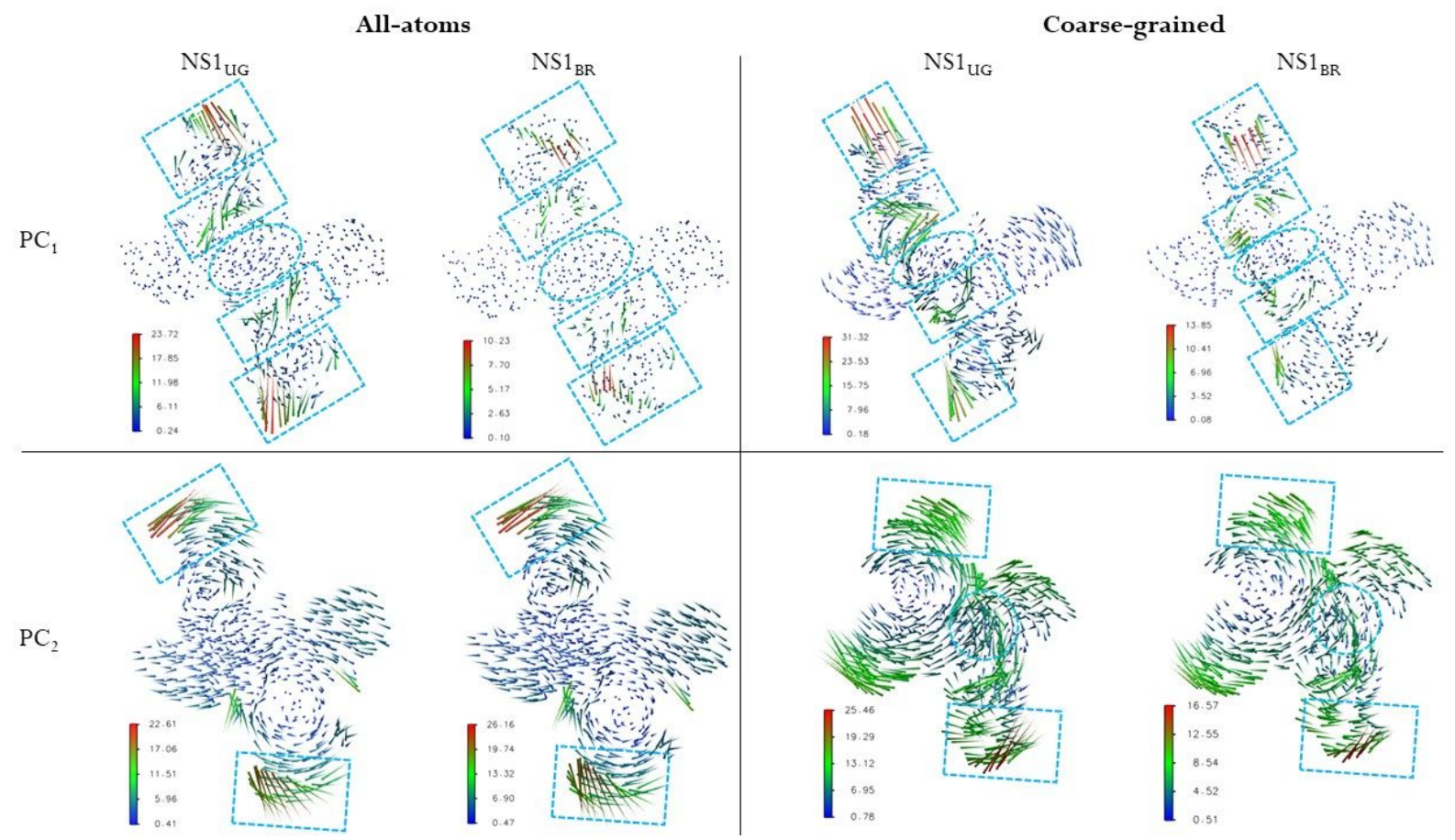

Figure S2. Porcupine plots for the first two PCs of $\mathrm{NS} 1_{\mathrm{UG}}$ and $\mathrm{NS} 1_{\mathrm{BR}}$ using all-atoms and coarsegrained modeling. Arrows indicate the direction of amino acid movement and scales in rainbows their amplitude. Dashed circles and rectangles refer to zones 1 and 2, respectively. 


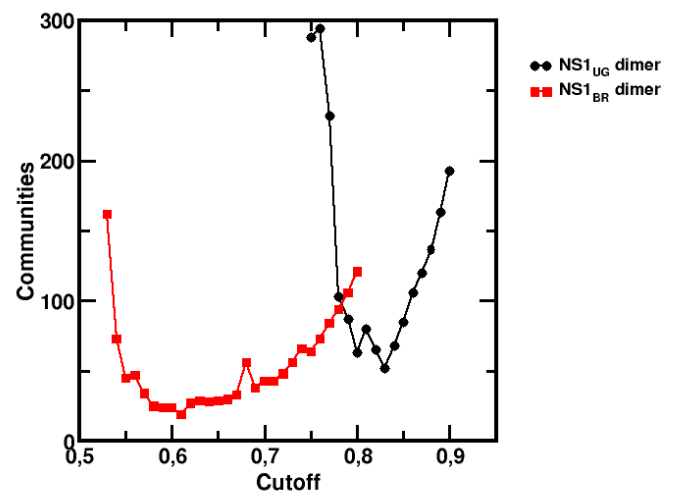

Figure S3. Correlation network analysis based on DCCM at the coarse-grained level. Communities as a function of the cutoff for $\mathrm{NS}_{\mathrm{UG}}$ and $\mathrm{NS} 1_{\mathrm{BR}}$.

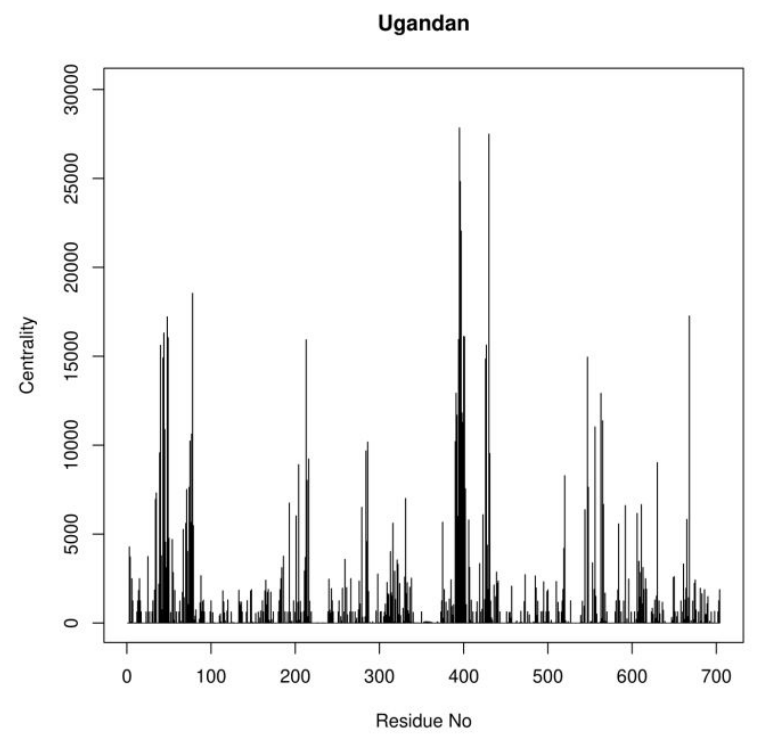

(a)

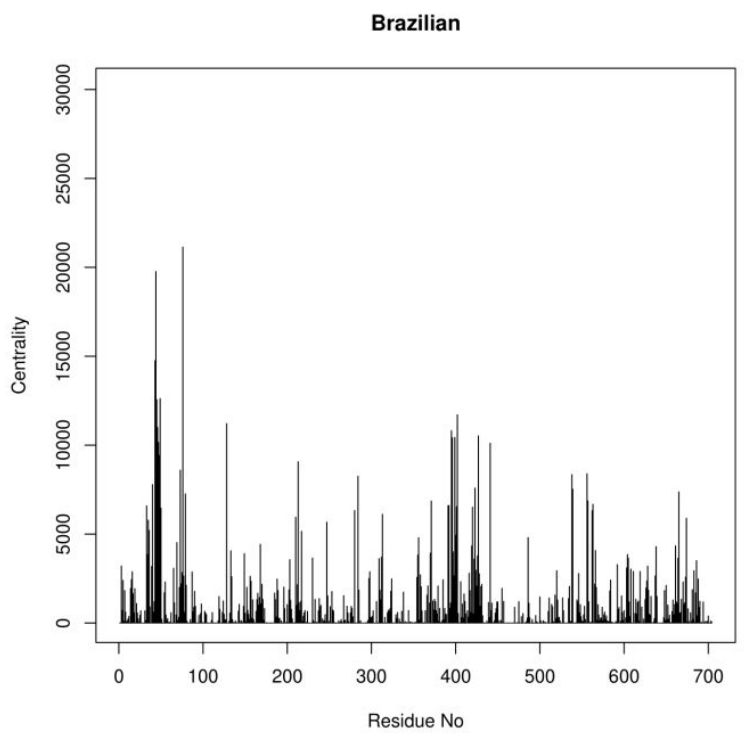

(b)

Figure S4. Centrality as a function of the number of residues for two $\mathrm{NS} 1_{\text {ZIKV }}$ at coarse-grained level. Note that the two chains of dimers are continuous from each other. 


\section{$\mathrm{NS}_{\text {UG }}$}

Positively correlated

Negatively correlated
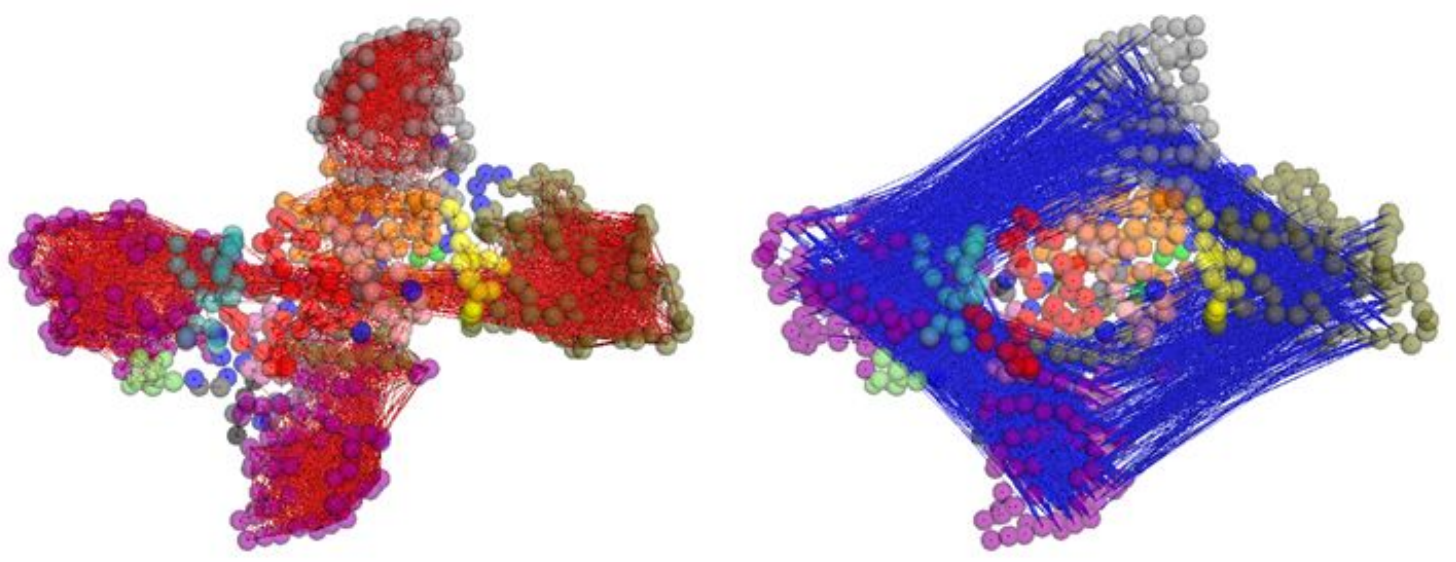

Ref. first figure

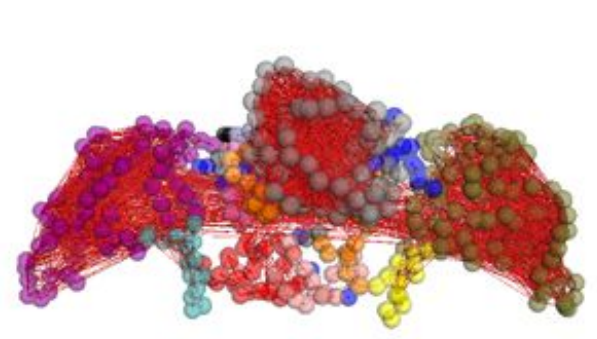

$90^{\circ}$
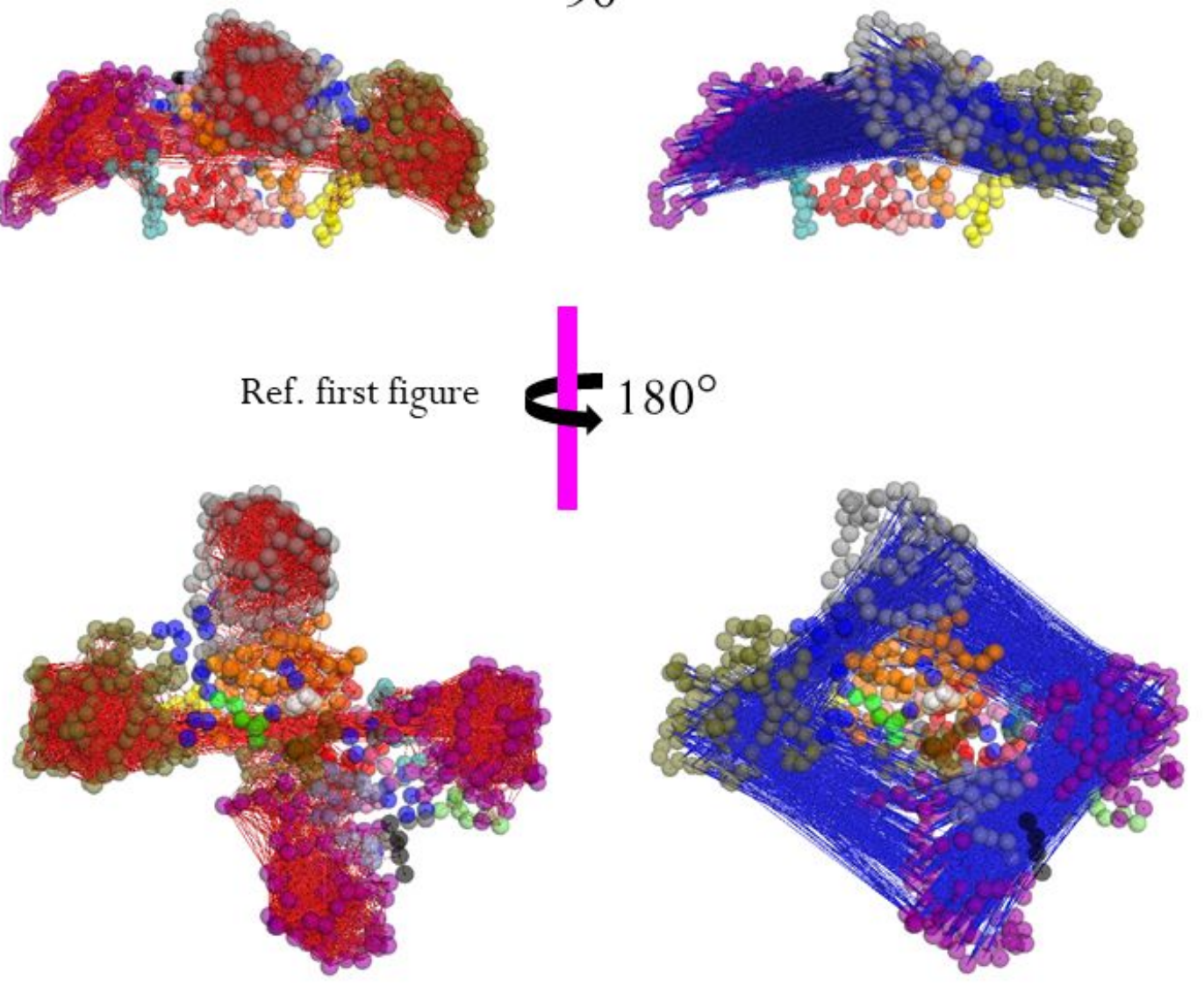

(a) 


\section{NS1 $1_{\text {BR }}$}

Positively correlated

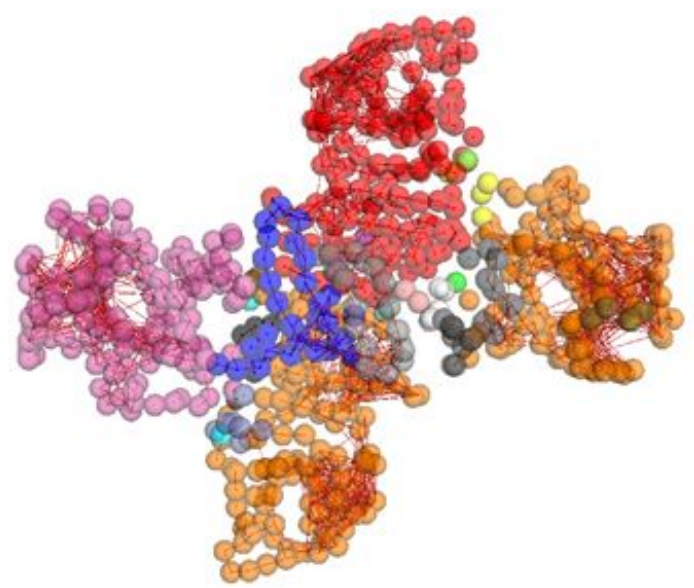

Ref. first figure

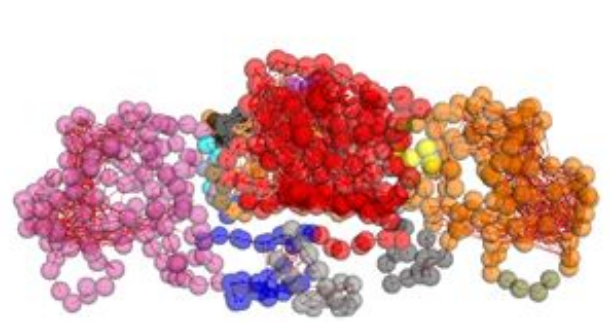

$90^{\circ}$
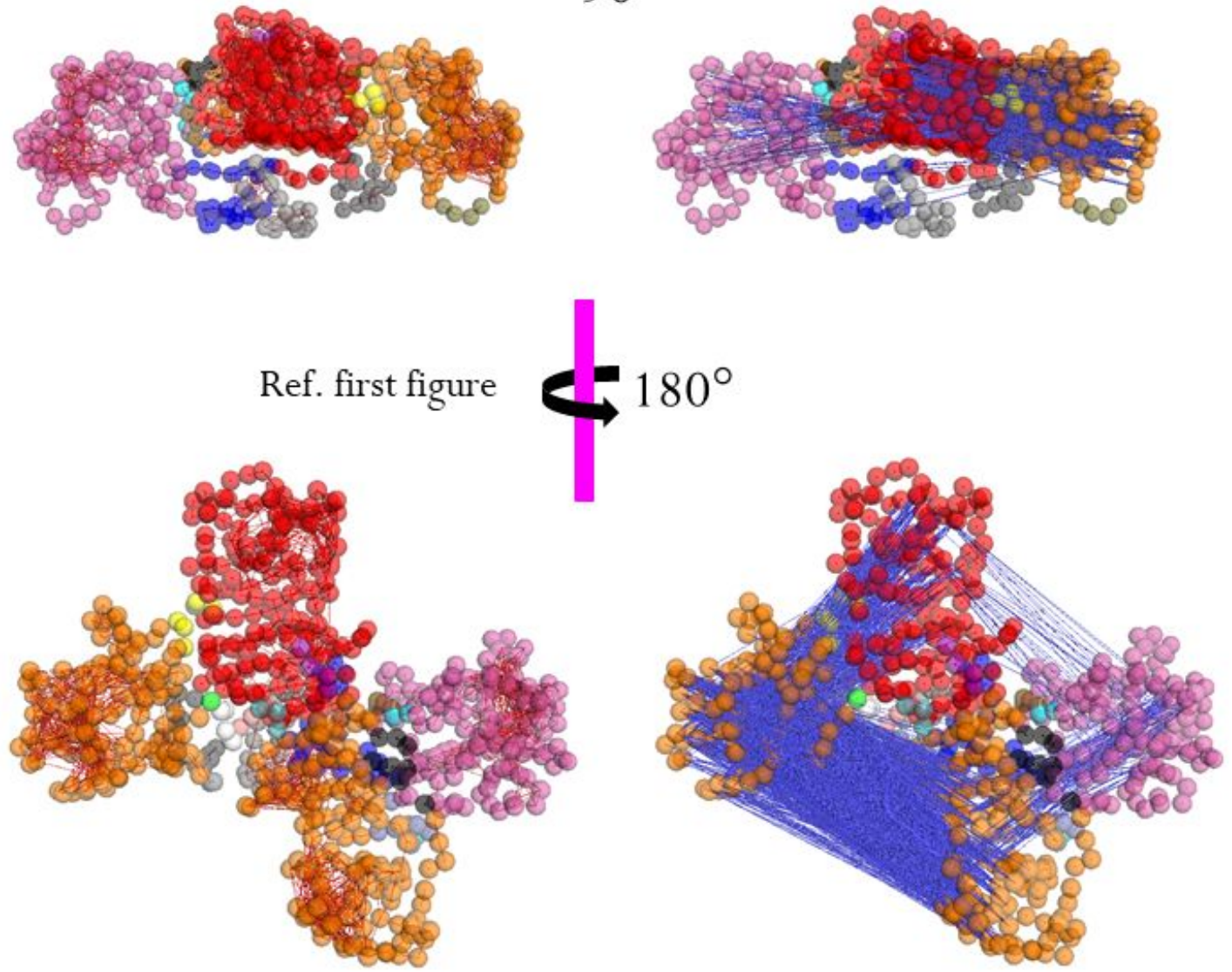

(b) 
Figure S5. Cross-correlation pattern for two ZIKV NS1 structure proteins. Data are based on DCCM analysis. Only the backbone is shown. Community colors for $\mathrm{NS}_{\mathrm{UG}}$ and $\mathrm{NS}_{\mathrm{BR}}$ are the same as those displayed at the bottom and vertical margins of DCCM plots in Figures 5a and 5b, respectively. Orientations are based on Figures $5 \mathrm{e}$ and $5 \mathrm{f}$.

Movie S1. Movies produced from the Molecular dynamics for two ZIKV NS1 proteins. Trajectories correspond to one of the replicates for (a) $N S 1_{U G}$ and (b) $N S 1_{B R}$. Only the backbone is shown in the movies. Colors follow the PSN communities analysis (see text for more details). Orientations are based on Figures 5e and 5f. Other sources: DOI:10.5281/zenodo.4500680. 